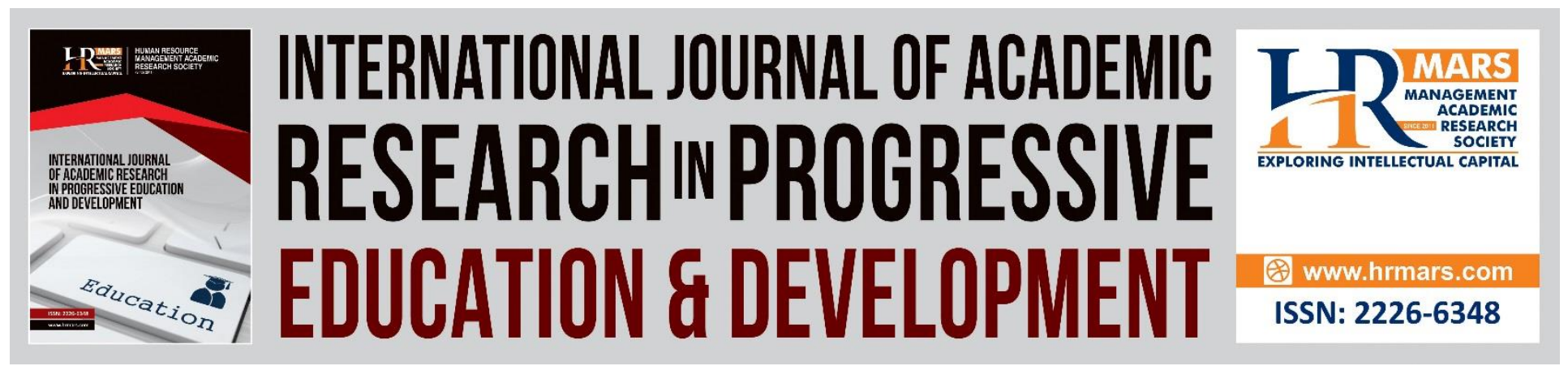

\title{
Bibliographic Control and Resource Description Access Standard in Malaysia
}

Che Zainab Hj Abdullah, Suriana Che Daud, Nor Zaina Zaharah Mohd Ariff, Norshila Shaifuddin

To Link this Article: http://dx.doi.org/10.6007/IJARPED/v7-i3/4350 DOI: $10.6007 /$ IJARPED/v7-i3/4350

Received: 03 June 2018, Revised: 21 June 2018, Accepted: 09 July 2018

Published Online: 23 July 2018

In-Text Citation: (Abdullah, Daud, Ariff, \& Shaifuddin, 2018)

To Cite this Article: Abdullah, C. Z. H., Daud, S. C., Ariff, N. Z. Z. M., \& Shaifuddin, N. (2018). Bibliographic Control and Resource Description Access Standard in Malaysia. International Journal of Academic Research in Progressive Education and Development, 7(3), 96-102.

Copyright: (c) 2018 The Author(s)

Published by Human Resource Management Academic Research Society (www.hrmars.com)

This article is published under the Creative Commons Attribution (CC BY 4.0) license. Anyone may reproduce, distribute, translate and create derivative works of this article (for both commercial and non-commercial purposes), subject to full attribution to the original publication and authors. The full terms of this license may be seen at: $\underline{\text { http://creativecommons.org/licences/by/4.0/legalcode }}$

Vol. 7, No. 3, July 2018, Pg. 96 - 102

http://hrmars.com/index.php/pages/detail/IJARPED

JOURNAL HOMEPAGE

Full Terms \& Conditions of access and use can be found at

http://hrmars.com/index.php/pages/detail/publication-ethics 


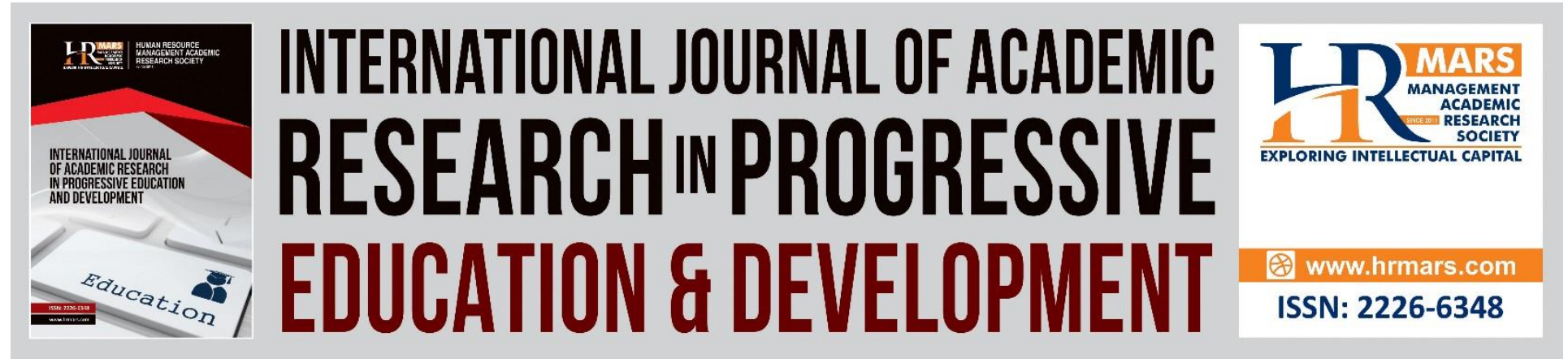

\title{
Bibliographic Control and Resource Description Access Standard in Malaysia
}

\author{
${ }^{1}$ Che Zainab Hj Abdullah, ${ }^{2}$ Suriana Che Daud, ${ }^{3}$ Nor Zaina \\ Zaharah Mohd Ariff, ${ }^{4}$ Norshila Shaifuddin \\ Faculty of Information Management, Universiti Teknologi MARA \\ Email: ${ }^{1}$ cheza347@salam.uitm.edu.my, ${ }^{2}$ suria481@salam.uitm.edu.my , \\ 3norzaina@salam.uitm.edu.my, ${ }^{4}$ norshila74@salam.uitm.edumy
}

\begin{abstract}
Technological advances and emergence of digital information present a significantly different challenge than libraries had before. With abundance of digital formats of information available in libraries, a new standard of cataloging has been introduced. The standard for cataloging that emphasized on the content of metadata which can support the discovery, identification and employment of information resources in library or known as Resource Description and Access (RDA) is designed for the digital environment. It is expected to have full implementation in all libraries in Malaysia by 2017. This announcement has been made by the former director of National Library of Malaysia. To accomplish this mission, training is considered a basic requirement for every librarian before the introduction of RDA. However, it is found to be great challenges in conducting training and implementation of RDA in many libraries. With regards to this matter this study focuses on literatures on RDA pertaining to; training, costs, cataloging procedures and integrated library system. The framework may become foundation for libraries in supporting RDA in bibliographic control. The insight will inspire and inform a wide array of new research agenda in the cataloging and metadata literature.

Keywords: Resource Description Access (RDA), bibliographic control, Cataloging Standard, Metadata Model, library science
\end{abstract}

\section{Introduction}

The development of computer technology and electronic document production presents a significantly different challenge than libraries had before. To make an effective transition to the new reality, librarians need to undertake a broad analysis of how the changing information technology and our rapidly evolving information resources are changing user behavior. This mean that a vision of cataloging department in library should have radical transformation. A new standard for cataloging which emphasized on the content of metadata used which support the 
Vol. 7, No. 3, July 2018, E-ISSN: 2226-6348 @ 2018 HRMARS

discovery, identification and employment of information resources in library known as Resource Description and Access (RDA) is designed for the digital environment was published in June 2010. It is a departure from its predecessor, the Anglo-American Cataloging Rules, second edition (AACR2), (Miller, 2011).

RDA aims at all end-users who need to find, identify, select, obtain, or use information, and all those who need to manage and organize information resources in a professional capacity. RDA deals only with metadata content, so it is independent of any specific technical storage or communication format (Dunsire, 2007). It introduces three new data elements based on the FRBR framework, namely; content type, media type, and carrier type than can be combined to accommodate both current and future types of resources.

The objective of this paper is to focus on RDA literature pertaining to training, costs, cataloging procedures and integrated library system and bibliographic control.

\section{Problem Statements}

Implementation of RDA is considered expensive and complex

RDA is not free. The pricing does put it out of the reach of many libraries. Furthermore, librarianship not a rich profession and technical services is usually on the short-end of the budgeting. The cost of a subscription alone will prevent small libraries from using RDA, and that the complexity will scare off potential users. The complexity is necessarily a problem in itself. As a number of individuals have pointed out that cataloguing is already very complex; MARC has fields that very few people understand or use, and more are being added to deal with RDAspecific information. The problem comes when catalogers familiar with AACR2 are asked to learn a new system from scratch, when the benefits of it are not readily apparent.

\section{Difficulties in delivering training}

Training is required for every librarian before implementing RDA in cataloging process. For instances, one of the main challenges of RDA implementation in Cambridge was simply the logistics of coordinating training and implementation across so many libraries. Developing and delivering training in this context is quite a big job in itself. Besides, the main issues were agreeing with policy for the various options and alternatives available in RDA and also making sure all the systems were able to display, index and interpret the new MARC fields. (Carty,2013).

\section{Literature Review Staff Training}

Training programs would need to be developed only once, and all staff would be "in it together." Everyone would have an opportunity to contribute to the process, and learn from one another at the same time, and we could test RDA application on a broader spectrum of resource types, subject domains, and cataloger expertise. A more holistic approach had the potential to foster organization-wide team building, avoiding the possibility of creating a privileged few who got to be part of a test and to keep up with regular production levels (Cronin, 2011).

Variety of methods for RDA training should be made available, including in-person workshops and webinars, while making no efforts to determine which format was the most effective or the most preferred training method. Web-based training as suggested, may be free or low-cost training program and will be in much greater demand within cataloging community in the United 
Vol. 7, No. 3, July 2018, E-ISSN: 2226-6348 @ 2018 HRMARS

States. This is because training budgets are strained or even nonexistent, and as many libraries have difficulties bringing in outside trainers for on-site local training or sending their staff to any extended training (Tosaka \& Park, 2013).

The study in Malaysia revealed that respondents acknowledged the inadequacy of their basic understanding of RDA. The study also identified the catalogers' needs and preference for RDA training. Most of the catalogers favored learning more about RDA context topics which include FRBR, Functional Requirements for Authority Data and International Cataloging Principles. They indicated willingness to undergo a two- to three-day intensive workshop to learn more about RDA (Yushiana \& Emilia, 2014).

\section{Costs}

Costs were largely unknown and having more staff involved meant that the need for consultation between them would increase; certainly, the management team would also need to expect a higher volume of questions from staff about how to do their work. In terms of subscribing to RDA, purchasing the code in print will initially seem like the least expensive option (Cronin, 2011). A key focus of many case studies was on understanding the real cost of RDA adoption. For example, while many authors observed that the RDA toolkit seemed expensive, they also tended to focus on non-set costs including personnel time, technology costs including expenses required to update systems to conform to RDA, and ongoing training costs ( Mitchell, 2013).

The cost of the updates for the print will be. It is likewise difficult to judge what the opportunity costs are of not subscribing to the online toolkit. For instance, the print version will not contain links between related RDA instructions, between RDA and the Library of Congress Policy Statements (the successor to Library of Congress Rule Interpretations), between RDA and MARC documentation, and the print version will obviously not be accessible through Cataloger's Desktop (Cronin, 2011). The cost of RDA itself is prohibitive for many libraries, training will be difficult and costly, and the learning curve will negatively and significantly affect all cataloging agencies (Sanchez, 2011)

The adoption of RDA comes with considerable costs including staff training, new information systems, and retrospective conversion. These costs are certainly a factor as the library profession considers the long-term viability of bibliographic standards including RDA and MARC (Mitchell, 2013).

\section{Cataloging Procedure}

Policies and procedures would have been more difficult to change in a flexible way when all staff were using them. Implementing with everyone at the same time might also mean a period of time when processing times were slower, as catalogers learned to apply new rules, policies, or procedures. (Cronin, 2011).

Several authors voiced the need for local policies and training to help guide catalogers in creating AACR2 and RDA records for the foreseeable future. These comments emphasized the implications of creating RDA records using old encoding standard (e.g., MARC), the implications on usability for patrons (e.g., the inability of the system to show both GMD and 33x data in the same way), and the need for consistent main entry creation and authority control (Mitchell, 2013). 
Vol. 7, No. 3, July 2018, E-ISSN: 2226-6348 @ 2018 HRMARS

Future research will require more in-depth studies of RDA's expected benefits and how the new cataloging code will improve resource retrieval and bibliographic control for users and catalogers alike over AACR2. In this regard, user research-perhaps the least studied area in RDA researchwill play a particularly important part in validating RDA's ability to support its key objective"responsiveness to user needs" - in the context of library catalogs. For example, there is a critical need to build an evidence base for evaluating how the additional information provided by RDAsuch as bibliographic relationships and content, media, and carrier types-will prove ever useful to end users

A comprehensive understanding of how RDA will affect the future of bibliographic control will better inform mechanisms for successful RDA implementation across the library profession and produce much better outcomes in easing catalogers' transition from AACR2 through adequate training and preparation (Tosaka \& Park, 2013).

\section{Integrated Library System}

The most immediate and obvious impact that RDA will have on library management systems (LMS) is improved integration of metadata content rules and guidance with cataloguing modules. RDA will be published as an online product offering direct access to individual rules, glossary terms and other specific content as well as structured navigation across and within its component parts. LMS vendors are being kept informed of RDA so that they can develop their cataloguing workflows, input and amendment templates, and context-sensitive help services to utilise the functionality of the RDA product. A proof-of-concept demonstrator of how this might work is available (Dunsire, 2007)

Libraries have various levels of control over their ILS systems. Some institutions have a lot of local ability (both technically and in terms of staff expertise) to configure their ILS, while others have almost no local control and are dependent on the vendor to push out updates and changes. When starting to think about implementation, institutions will want to consult any documentation the ILS vendor has distributed with regard to its readiness for RDA. It may also be useful to contact testers or early adopters who have the same ILS to see how they handled the shift. System administrators who may not be catalogers themselves, are going to require at least some knowledge of what new data will be contained in RDA MARC records-at least enough to know what needs to be done in the local system to accommodate the data. There are two main areas where administrators should focus attention in this regard. The first is the suite of new or modified fields in the MARC bibliographic and authority formats. For institutions that have not employed relator terms in their catalog systems before, the second area of concern may be the increased emphasis and ability with RDA to use relationship designators (manifested as relator terms and/or codes in MARC) for entities related to the resource being described. (Cronin, 2011).

\section{Bibliographic Control}

Bibliographic control is the process by which information resources are described, so that they are easily accessible for users. By creating a bibliographic record regarding an information resource, and then indexing it on a database or search engine, users are able to locate the resource and find out whether or not it is relevant to them (LIANZA, 2014). According to Hagler (1991) among the functions of bibliographic control. 
Vol. 7, No. 3, July 2018, E-ISSN: 2226-6348 @ 2018 HRMARS

i. Identifying the existence of all types of information resources as they are made available. The existence and identity of an information resource must be known before it can be found.

ii. Providing the means of locating each information resource or a copy of it. In libraries, the online public access catalogue (OPAC) can give the user location information (a call number for example) and indicate whether the item is available.

Patrick Wilson (1968), emphasizes that it takes as its purpose the delivery of the best textual means to an end, which requires the development of tools (what Wilson calls bibliographical instruments) that offer control over a body of writings. Bibliographic control, made manifest in catalogues, exists in the context of libraries and bibliographic utilities, like the WorldCat database.

Bibliographic control also focuses to International standard bibliographic description ( ISBD) regularises the form and content of bibliographic descriptions. It mainly deals with description of resources and is not directly concerned with access points or authority control since it was created long before the possibilities offered by computerized data processing were understood. A key advantage of ISBD is that it is a concise rule set that produces an easy to understand, human readable representation of a bibliographic record that can be understood without knowing the language of the resource (IFLA, 2017).

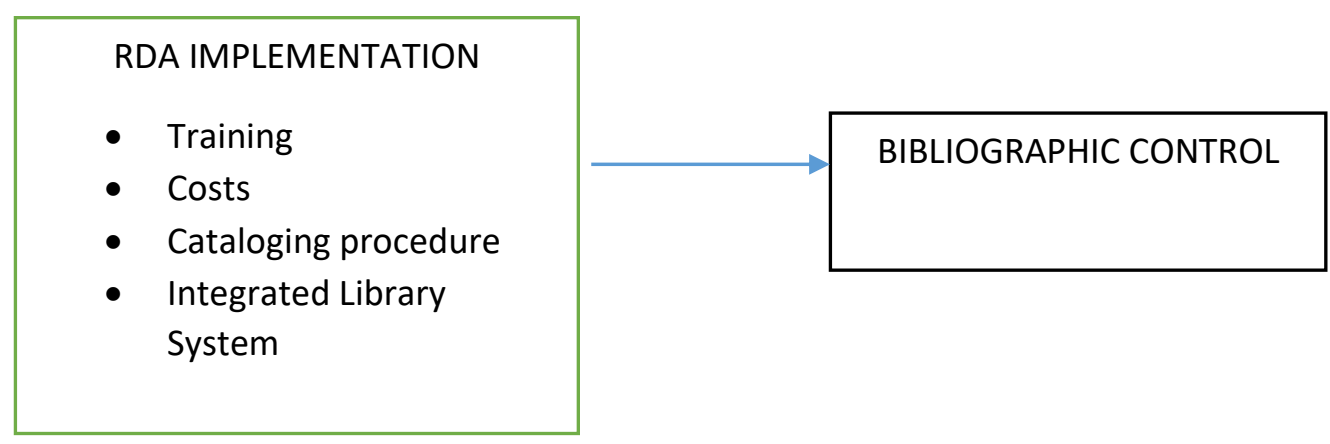

Figure 1: Framework of Resource Description Access (RDA) and Bibliographic Control

\section{Conclusion}

The study provides framework and guideline to the top level management in libraries in implementing RDA. It could be of interest to both researchers and libraries' stakeholders, as it has significantly and enriched the body of knowledge. Library information Science (LIS) trainers, educators, and researchers will gain from this article a clearer understanding of RDA pertaining to; training, costs, cataloging procedures, integrated library system that would better meet practitioners' needs during the transition in library cataloging standards. Series of workshops will bring exposure and understanding to librarians on how to use the new international cataloguing standards and rules (RDA) to document library materials in various formats and in using the RDA Toolkit in preparation for the implementation of RDA in Malaysia. Necessary funding might obtain from ASEAN COCl Cultural Fund to organize a workshop on RDA in documenting library resources for young librarians. 
INTERNATIONAL JOURNAL OF ACADEMIC RESEARCH IN PROGRESSIVE EDUCATION AND DEVELOPMENT

Vol. 7, No. 3, July 2018, E-ISSN: 2226-6348 @ 2018 HRMARS

\section{References}

Carty, C. (2013). Implementing RDA in Cambridge University Library. Cambridge: University Library and member of the Cambridge RDA Steering Group.

Cronin, C. (2011) From Testing to Implementation: Managing Full-Scale RDA Adoption at the University of Chicago Cataloging \& Classification Quarterly, 49:7-8.

Dunsire, G. (2007). RDA and library systems, BID (biblioLioteconomia I documentacio, 19 (dis).

Hagler, R. (1991). The Bibliographic Record and Information Technology. 2nd ed. Chicago: American Library Association, 245-249.

IFLA (2017) Retrieved from https://www.ifla.org/best-practice-for-national-bibliographicagencies-in-a-digital-age/node/8911

LIANZA (2014). 5 Minutes on Bibliographic Control. Retrieved from https://lianza.org.nz/5minutes-bibliographic-control

Miller, I. (2011).Resource Description and Access (RDA) An Introduction for Reference Librarians. Reference service quarterly. 50 ( 3 ) Spring .

Mitchell, E. (2013). Is RDA Ready?: An Analysis of Case Studies on RDA TestingTechnical Services Quarterly. 30 (1).

Raslin, A. B. (2014) In Asean Member States Annual Report 22nd Meeting Of Directors Of National Libraries In Asia And Oceania (Cdnlao) 2014.

Sanchez, E. R. (2011). RDA, AACR2, and you: what catalogers are thinking.

Tosaka, Y. \& Park, J. (2013).RDA: Resource description \& access-a survey of the current state of the art. Journal of the Association for Information Science and Technology. 64 (4), 651-662.

Yushiana, M. \& Emilia, R. (2014) "RDA perceptions among Malaysian catalogers", Library Review, Vol. 63 Iss: 3, pp.176-188 